\title{
Paranazal Sinüs Bilgisayarlı Tomografi incelemeleri ile Keros Sınıflaması ve Kribriform Plate Derinliği Asimetrisinin Değerlendirilmesi
}

\author{
Keros Classification And Evaluation of Cribriform Plate Depth \\ Asymmetry Of The Population In Marmara Region
}

\author{
Ahmet Kara, Halil Elden, Mehmet Guven, Mahmut Sinan Yilmaz, Deniz Demir \\ Sakarya Üniversitesi Tıp Fakültesi Eğitim ve Araştırma Hastanesi, KBB ABD, Sakarya, Türkiye \\ Yazışma Adresi / Correspondence: \\ Ahmet Kara
}

Sakarya Universitesi Eğitim ve Araştırma Hastanesi, 54000, Korucuk, Sakarya, Türkiye

T: $905307716317 \quad$ E-mail: doktor.kbb@hotmail.com

Geliş Tarihi / Received : 14.01.2018 Kabul Tarihi / Accepted : 10.04.2018

\footnotetext{
Öz

Amaç Bu radyo-anatomik çalışma ile bölgemizdeki 18 yaş altı ve üstü populasyonun anterior kafa tabanı anatomisi ile ilgili veri elde etmek ve normatif verilerin elde edilmesi ile komplikasyon oranlarının azaltııması amaçlanmıștır.

Sakarya Tip Dergisi, 2018, 8(2):352-358 )

Gereç ve Çalısmaya 7-18 yaș arası 100 kiși, 18-50 yaș arası 100 kiși olmak üzere toplam 200 kiși dahil edildi. Koronal planda çekilmiș bilgisayarlı

Yöntem tomografi görüntüleri dijital ortamda kemik pencerede incelendi. Olfaktor fossa derinlik ölçümleri yapıldı ve sonuçlar istatistiki yöntemler ile karşılaştıııldı.

Bulgular Pediatrik grubun yas ortalaması 13,4 $\pm 2,73$ (erkek: $13,1 \pm 2,63$, bayan: $13,6 \pm 2,82$ ), eriskin grubun yas ortalaması $39,9 \pm 7,46$ (erkek: $40,6 \pm 7,82$, bayan: $39,3 \pm 7,11)$ idi. Pediatrik ve erișkin grup lamina lateralis derinlikleri açıınndan karșılaștıııldığında aradaki fark istatistiki anlam oluşturmadı. Yine pediatrik ve erişkin gruplar kendi içlerinde cinsiyet farkılı̆ı̆ı, sağ ve sol taraf asimerisi bakımından karşılaştıııdığında istatistiki anlamlı fark oluşmadı. Pediatrik grupta \%15, erişkin grupta \%18 oranında keros asimetrisi tespit edildi.

Sonuç Çalıșmada gerçekleștirilen ölçümler sonucunda istatistiki olarak anlam ifade etmese de asimetrik keros vakaları konusunda cerrahın dikkatli olması gerekliliği literatür ile uyumlu bir şekilde tekrar vurgulanmıștır. Pediatrik yaş grubundaki farklııklar için ise geniş katılımcı sayıları ile çalışmanın tekrarlanması önerilebilir

Anahtar Etmoid çatı; Bilgisayarlı tomografi; kafa tabanı, keros sınıflaması

Kelimeler
}

\footnotetext{
Abstract

Purpose With this radio-anatomic study, it is aimed to get the data of the anterior skull base anatomy of the population under and over 18 years old to reduce the complication rates by obtaining normative data. ( Sakarya Med J, 2018, 8(2):352-358 ).

Materials and A total of 200 participants, including 100 participants aged 7-18 years and 100 participants aged $18-50$, were included in the study. The

Methods coronal paranasal sinus computed tomography cross-sections were examined using a digital screen. Olfactory fossa depth measurements were made and the results compared with statistical methods.

Results The mean age of the pediatric group was $13,4 \pm 2,73$ (male: $13,1 \pm 2,63$, female: $13,6 \pm 2,82$ ) and the mean age of the adult group was $39,9 \pm 7,46$ (male: $40,6 \pm 7,82$, female: $39,3 \pm 7,11$ ). When the pediatric and adult groups were compared in terms of depth of lamina lateralis, the difference was not statistically significant. There was no statistically significant difference between the pediatric and adult groups in terms of gender difference and right and left side asymmetry. Keros asymmetry was detected in $15 \%$ in pediatric group and $18 \%$ in adult group.

Conclusion As a result of the measurements, although it is not statistically significant, it must be emphasized that the surgeon must be alarmed about the asimetry of keros classification. For the differences in the pediatric age group, it is advisable to repeat the study with large numbers of participants.

KeyWords Etmoid roof; Computed Tomography; cranial base; keros classification
} 
Sakarya TIp Dergisi 2018;8(2):352-358

\section{Giriş}

Fonksiyonel endoskopik sinüs cerrahisi paranazal sinüs ostiumlarının direk endoskopik görüş altında açılmasını amaçlayan ve Kulak Burun Boğaz (KBB) pratiğinde oldukça sık uygulanan bir cerrahi yöntemdir. Kronik sinüzit ve nazal polipozis başta olmak üzere birçok sinonazal hastalığın tedavisinde kullanılmaktadır. Bu cerrahi teknikte endoskop yardımıyla tüm paranazal sinüslere ulaşılabilmekte ve tüm paranazal sinüs ostiumları açılabilmektedir. Ancak bu cerrahiyi gerçekleştirmeden önce cerrahın paranazal sinüsler ve özellikle orbita ve anterior kafa tabanı gibi yakın komşuluklarının anatomisini çok iyi bilmesi, cerrahi işlem öncesinde radyolojik tetkikleri analiz edebilmesi ve cerrahi işlemleri bu anatomi bilgisi ve cerrahi yol göstericileri kullanarak gerçekleştirmesi gerekmektedir.

Anterior kafa tabanı travmaları ve buna sekonder BOS fistülleri fonksiyonel sinüs cerrahilerinin en önemli komplikasyonlarındandır. Literatür bilgisine göre bu komplikasyonların en sık kribriform plate lateral lamellasında oluştuğu bilinmektedir. Özellikle anterior etmoid arterin kafa tabanın penetre ettiği nokta tüm kafa tabanının en düşük dirençli alanı alarak kabul edilmektedir. ${ }^{1}$ Etmoid çatı anatomisi ile ilgili yapılan anatomik çalışmalar ile 1960' lı yılların başında olfaktor fossa Keros tarafından lateral lamina uzunluğuna göre üç kategoriye ayrılmış olup günümüzde dahi bu sınıflama güncelliğini korumaktadır. ${ }^{2}$

Paranazal sinüslerin bilgisayarlı tomografi (BT) incelemesi endoskopik sinüs cerrahisi öncesinde çok önemli bir tetkik olarak uzun sürelerdir kullanılmakta ve radyoloji uzmanlarına ek olarak mutlaka bölge ile ilgilenen cerrahlar tarafından da yorumlanabilmelidir. Yapılan çalışmalarda çeşitli etnik gruplarda olfaktor fossa derinliğinin değişkenlik gösterdiği saptanmıştır. Bu radyo-anatomik çalışma ile bölgemizdeki 18 yaş altı ve üstü populasyonun anterior kafa tabanı anatomisi ile ilgili veri elde etmek ve normatif verilerin elde edilmesi ile komplikasyon oranlarının azaltılması amaçlanmıştır.

\section{Materyal ve Yöntem}

Araştırma protokolü Sakarya Üniversitesi Etik Kuruluna başvurularak, etik kurallar ve Helsinki Deklerasyonuna ve Türk kanun ve yasalarına uygun olarak gerçekleştirilmiştir. Bu tanımlayıcı çalışmada 1 Ocak 2016 - 31 Aralık 2016 tarihleri arasında Sakarya Üniversitesi Eğitim ve Araştırma Hastanesi KBB hastalıkları kliniği'nde çeşitli nazal şikayetler nedeniyle çekilen paranazal sinüs BT incelemeleri retrospektif olarak tarandı ve kulak burun boğaz hastalıkları uzmanı tarafından incelendi. Çaışmaya 7-18 yaş arası 100 kişi, 18-50 yaş arası 100 kişi olmak üzere toplam 200 kişi dahil edildi. Geçirilmiş kafa tabanı veya paranazal sinüs cerrahi öyküsü, konjenital yüz anomalisi, etmoid çatıda erozyona neden olan mevcut yada geçirilmiş hastalık öyküsü, kromozomal anomali mevcudiyeti çalışmadan çıkarılma kriterleri olarak kabul edildi. İncelemelerde 64 dedektörlü bilgisayarlı tomografi cihazı (Toshiba Aquilion 64MDCT) kullanıldı. Hastalara yüz üstü pozisyonda baş ekstansiyona getirilerek gerçekleştirilen BT incelemeleri ile 3 mm lik kesit kalınlığında koronal planda görüntüler elde edildi. İncelemeler dijital ortamda kemik pencerede KBB hastalıkları uzmanınca incelendi.

Etmoid çatı ölçümleri dijital ekranda manuel yolla gerçekleştirildi. Ölçümler sırasında standart anatomik noktalar kullanılarak ölçümler standardize edildi. ${ }^{3}$ Bu noktalar; her iki infraorbital siniri birleştiren horizontal çizgi, kribriform plate ve etmoid çatının medial noktası (etmoid çatının lamina lateralis ile birleşme noktası) olarak belirlenmiştir. İnfraorbital sinirleri birleştiren horizontal çizgiden 
etmoid çatı medial noktasına dik çekilen vertikal çizgi uzunluğu medial etmoid çatı yüksekliği olarak belirlendi. İnfraorbital sinirleri birleştiren horizontal çizgiden lamina kribrozaya dik çekilen vertikal çizgi uzunluğu ise kribriform plate yüksekliği olarak belirlendi. ỉki yükseklik arasındaki fark ise lamina lateralis yüksekliği olarak kabul edildi (figür 1). Elde edilen verilere göre; 1-3 mm arasındaki derinlikler keros 1, 4-7 mm arası keros 2, 8-16 mm arası ise keros 3 olarak kabul edildi ve istatistiki analizler bu değerler esas alınarak gerçekleştirildi.

\section{İstatistiksel analiz}

Windows için IBM SPSS 20.0 versiyon istatistiksel yazlım programı (IBM Corporation, Armonk, New York, USA) kullanılarak yapıldı. Sürekli değişkenler için ortalama \pm standart sapma, kategorik değişkenler için ise yüzdelik değerler kullanıldı. Normallik dağıım analizleri için Kolmogorov-Smirnov analizi yapıldı ve bu analiz sonucu parametrik testler tercih edildi. Gruplar arası ikili karşışşırmalarda bağımsız örneklem T testi kullanıldı. Kategorik değişkenlerin karşılaştııılması için ise ki-kare testi kullanıldı. 0,05 den daha düşük $p$ değerleri istatistiki olarak anlamlı kabul edildi.

\section{Bulgular}

7-18 yaş arası 100 kişi, 18 -50 yaş arası 100 kişi olmak üzere toplam 200 kişi çalışmaya dahil edildi ve 400 taraf incelemeye alındı. Pediatrik yaş grubundaki hastaların \% 53' ü bayan (n:53), \%47’si erkek (n:47) idi. Erişkin hasta grubunda ise hastaların \% 51'i (n:51) bayan, \%49 (n:49) kadarı ise erkek idi. Pediatrik grubun yaş ortalaması $13,4 \pm 2,73$ (erkek: $13,1 \pm 2,63$, bayan: $13,6 \pm 2,82$ ), erişkin grubun yaş ortalaması $39,9 \pm 7,46$ (erkek: $40,6 \pm 7,82$, bayan: $39,3 \pm 7,11$ ) idi. Erişkin ve pediatrik gruplar cinsiyet gruplarına göre yaş ortalamaları bakımından kendi içlerinde karşılaştırıldığında istatistiki anlamlı farkın oluşmadığı görüldü ( $p:>0,05)$.

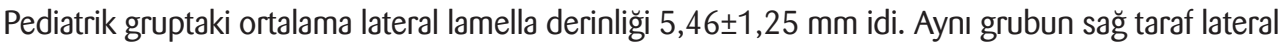
lamella derinliği $5,46 \pm 1,40 \mathrm{~mm}$, sol taraf lateral lamella derinliği 5,46 $\pm 1,32 \mathrm{~mm}$ idi. Keros sınıflamasına göre karşılaştııılığında hastaların \%15 kadarında keros asimetrisi izlendi. Numerik veriler karşılaştıııldığında sağ ve sol taraf arasındaki fark istatistiki anlamlı değildi ( $p>0,05)$. Pediatrik gruptaki bayan katılımclarda bu derinlik sağ ve sol taraf için sırasıyla $5,70 \pm 1,41 \mathrm{~mm}$ ve $5,65 \pm 1,30 \mathrm{~mm}$

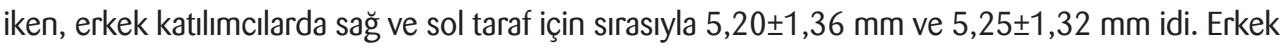
ve bayan katılımcılar kendi içlerinde yön açısından karşılaşııııldığında sağ ve sol taraf açısından istatistiki anlamlı bir fark görülmedi $(p>0,05)$. Yine ortalama lamina lateralis derinlikleri, cinsiyet gruplarına göre karşılaştıııldığında aradaki fark istatistiki olarak anlamlı değil idi (Bayan: 5,68ะ1,22, Erkek: 5,22 $\pm 1,25$ ) (tablo 1). Keros sınıflamasına göre değerlendirildiğinde ise; olguların \%2,5 inde Keros tip 1, \%83,5' inde Keros tip 2, \%14 kadarında ise Keros tip 3 varyantı izlendi. (tablo 2).

\begin{tabular}{|c|c|c|c|c|c|c|}
\hline & \multicolumn{3}{|c|}{ Pediatrik grup } & \multicolumn{3}{|c|}{ Erişkin grup } \\
\hline & Sağ & Sol & $\mathrm{P}$ değeri & Sağ & Sol & $P$ değeri \\
\hline Kadın & $5,70 \pm 1,41$ & $5,65 \pm 1,30$ & $p>0,05$ & $5.63 \pm 1.48$ & $5.67 \pm 1.55$ & $p>0,05$ \\
\hline Erkek & $5,20 \pm 1,36$ & $5,25 \pm 1,32$ & $p>0,05$ & $5.81 \pm 1.45$ & $5.76 \pm 1.59$ & $p>0,05$ \\
\hline Ortalama & $5,46 \pm 1,40$ & $5,46 \pm 1,32$ & $p>0,05$ & $5.72 \pm 1.46$ & $5.71 \pm 1.56$ & $p>0,05$ \\
\hline
\end{tabular}

Pediatrik hasta grubu kendi içinde 13 yaş altı (n:57) ve 13 yaş üstü (n:43) olmak üzere ikiye ayrıldı.
Sakarya Tıp Dergisi $2018 ; 8(2): 352-358$

KARA ve Ark.

Paranazal Sinüs BT ile Keros ve

Kribriform Asimetrisinin Değerlendirilmesi 
Sakarya TIp Dergisi 2018;8(2):352-358

KARA ve Ark. Paranazal Sinüs BT ile Keros ve Paranazal Sinüs BT ile Keros ve
Kribriform Asimetrisinin Değerlendirilmes
Gruplar hem numerik hem de kategorik değerler açısından karşılaştıııldığında; hem lamina lateralis derinliği, hem de keros tipleri açısından aradaki fark istatistiki anlam oluşturmadı.

Erişkin gruptaki ortalama lateral lamella derinliği $5,72 \pm 1,41 \mathrm{~mm}$ idi. Ortalama lateral lamella derinliği incelendiğinde ise sağ taraf lateral lamella derinliği $5,72 \pm 1,46 \mathrm{~mm}$, sol taraf lateral lamella derinliği 5,71 $\pm 1,56$ mm idi. Keros sınıflamasına göre karşılaştııılığında hastaların \%18 kadarında keros asimetrisi izlendi. Numerik veriler karşılaştırıldığında sağ ve sol taraf arasındaki fark istatistiki anlamlı değildi $(p>0,05)$. Erişkin gruptaki bayan katılımcılarda bu derinlik sağ ve sol taraf için sırasıyla $5,63 \pm 1,48 \mathrm{~mm}$ ve $5,67 \pm 1,55 \mathrm{~mm}$ iken, erkek katılımcılarda sağ ve sol taraf için sırasıyla

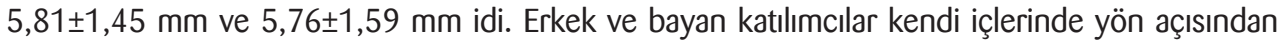
karşılaştıııldığında sağ ve sol taraf açııından istatistiki anlamlı bir fark görülmedi $(p>0,05)$ (tablo1). Yine ortalama lamina lateralis derinlikleri, cinsiyet açısından karşılaştıııldığında aradaki fark istatistiki olarak anlamlı değil idi (Bayan:5,65 $\pm 1,43$, Erkek:5,78 $\pm 1,40$ ) Keros sınıflamasına göre değerlendirildiğinde ise; Keros 1 olguların \%3,5 inde, Keros $2 \% 74$, Keros 3 ise $\% 22,5$ oranın da izlenmiştir (tablo 2).

Tablo2. Olfaktor fossa anatomisinin Keros sınıflaması ve gruplara göre sıklıkları

\begin{tabular}{|l|c|c|c|}
\hline & Keros 1 & Keros 2 & Keros 3 \\
\hline Pediatrik grup & $\% 2.5$ & $\% 83.5$ & $\% 14$ \\
\hline Erişkin grup & $\% 3.5$ & $\% 74.0$ & $\% 22.5$ \\
\hline P değeri & $\mathrm{p}>0,05$ & $\mathrm{p}>0,05$ & $\mathrm{p}>0,05$ \\
\hline
\end{tabular}

Erişkin ve pediatrik gruplar yön ayrımı olmadan lamina lateralis uzunluk ortalamaları açısından karşılaştıııldığında aradaki fark istatistiki olarak anlamlı değildi $(p>0,05)$. Yine Keros tipleri açısından bakıldığında erişkin grupta keros tip 3 sıklığı pediatrik gruba göre daha sık olsa da aradaki farkın istatistiki anlam oluşturmadığı görüldü $(p>0,05)$.

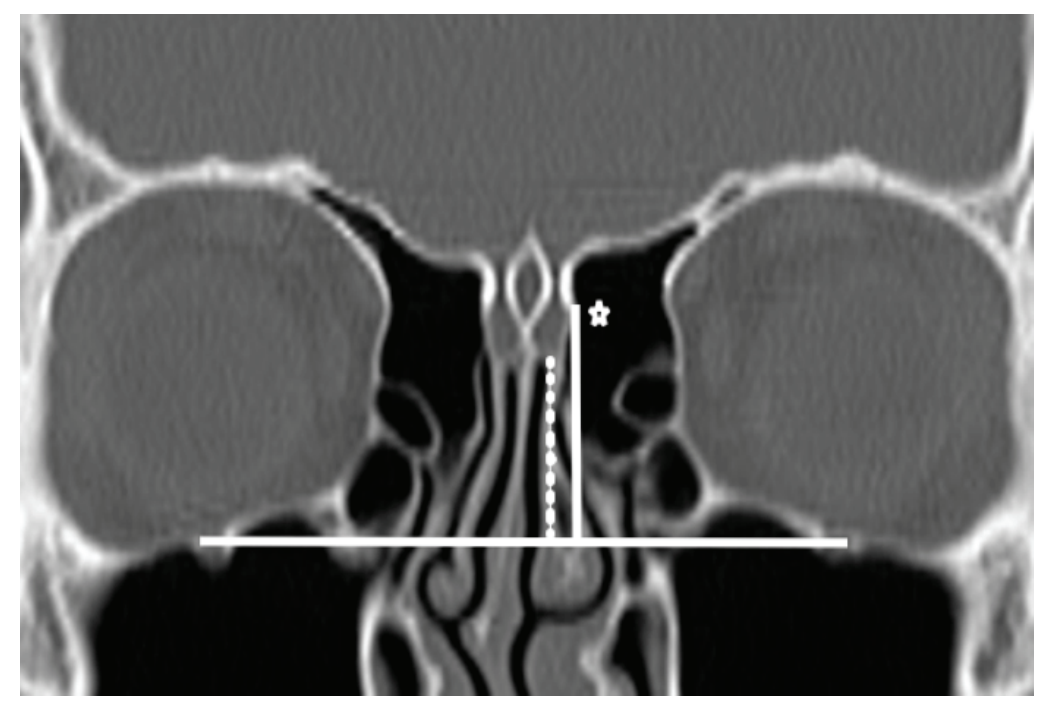

Figür 1: Olfaktor fossa derinlik ölçümlerinde kullanılan anatomik mesafeler

\section{Tartışma}

Günümüzde endoskopik sinüs cerrahisi klinik tedaviye dirençli kronik sinuzit, mukosel, nazal polipozis, lakrimal kanal obstrüksiyonuna bağlı epifora gibi durumlarda tedavi seçeneği olarak 
nial penetrasyon cerrahi sırasında az da olsa görülebilen komplikasyonlardan bazılarıdır. Bahsi geçen major komplikasyonlar ethmoid ve frontal sinüslerin cerrahi manüplasyonu ile ilişkilidir. ${ }^{1,5}$ Lateralde frontal kemiğin orbital parçası ile birleşen etmoid kemiğin lamina lateralisi anterior kafa tabanının en zayıf noktalarındandır. ${ }^{6}$ Dolayısı ile bu lamina derinleştikçe anterior kafa tabanını ilgilendirebilecek pek çok girişimde travmatize olma olasılığı da artmaktadır.7 Sonuç olarak bölge anatomisinin daha iyi bilinmesinin ve buna uygun cerrahi yaklaşımların komplikasyon olasılığını azaltabileceği söylenebilir. ${ }^{1}$

1962 ylında Keros olfaktör fossa derinliğini 3 ayrı kategoriye ayırarak tanımlamıştır. ${ }^{2}$ Keros tip $1 ; 3$ $\mathrm{mm}$ den küçük olfaktor fossa derinliğini ifade ederken, Keros tip 2 de 4-7 mm, Keros tip 3 de ise 8-16 mm arasındaki olfaktor fossa derinliği ifade edilmektedir. Dolayısı ile tip 3 cerrahi riskin en yüksek olduğu tiptir.8 Literatür incelendiğinde keros tip 2 nin en sık görüldüğü çeşitli çalışmalarda gösterilmiştir.1,9,10 Bizim çalışmamızda da hem pediatrik hasta grubunda hem de erişkin grupta literatüre benzer şekilde keros tip 2 yüksek oranda görülmüştür. Tip 1 keros varyantının her iki grup için de literatür ile karşılaştırıldığında daha az sıklıkla görüldüğü söylenebilir., ${ }^{2,911-14}$ Keros asimetrisi ile ilgili yapılan çalışmalar incelendiğinde; \%59 oranında keros asimetrisinin tespit edildiği makaleler bulunsa da, benzer yöntemler ile bu oranı \%9,5, \%10, \%12 gibi oranlarda bulan çalışmalar da bulunmaktadır. ${ }^{15-18}$ Bizim çalışmamızda bu oran; pediatrik grup için $\% 15$, erişkin grupta ise \% 18 olarak bulunmuştur. Literatür ile uyumlu olan bu bulgular temelinde endoskopik sinüs cerrahisi ile ilgilenen cerrahların bu farklılık konusunda bilgili ve dikkatli olmasının komplikasyon oranlarının azaltılmasında faydalı olacağı düşüncesindeyiz.

Elwany ve arkadaşlarının yaptığı çalışmada bayan ve erkeklerin laterel lamella derinlikleri ve keros tipleri karşıaştıııımış ve sonuç olarak lateral lamella uzunluklarının erkek hastalarda kadınlara göre istatistiki anlamlı fark oluşturacak şekilde daha fazla olduğu ve erkeklerde daha sıklıkla tip 2 keros varyantı görülürken, kadınlarda tip 1 varyantın daha sık görüldüğü tespit edilmiştir. ${ }^{18}$ Bizim çalışmamızda ise kadın ve erkek hastalar arasında istatistiki anlam oluşturacak bir farkılık izlenmemiştir. Literatür ile oluşan uyumsuzluk toplumsal farklılıklar ile ilişkilendirilebilir.

Pediatrik yaş grubunda yapılan sınırlı çalışmalarda farklı klinik sonuçlar raporlanmıştır. Başak ve arkadaşlarının 64 pediatrik, 111 erişkin katılımcı ile yaptıkları farkı iki çalışmanın sonuçları karşılaştııılığında; pediatrik grupta tip 1 varyantın daha az, tip 3 varyantın ise daha fazla olduğu görülmektedir. ${ }^{9,13}$ Anderhuber ve arkadaşlarının yaptığı çalışmada; erişkin grup ile pediatrik yaş grubu arasında fark bulunmamışırı. ${ }^{12}$ Guldner ve arkadaşlarının yaptığı farklı bir çalışma da ise Başak ve arkadaşlarının aksine pediatrik grupta keros tip 1 daha sık, keros tip 3 daha nadir görülmüştür. ${ }^{14}$ Guldner ve arkadaşları bu farkın etmoid çatının muhtemelen erişkin dönemde de gelişimine devam ettiği hipotezi ile açıklamıştır. Ancak sonuçlar önceki çalışmalar ile çelişmektedir. Bizim yaptığımız çalışmada da Guldner ve arkadaşları ile benzer şekilde keros tip 3 varyantı erişkin dönemde daha sık görülmüşsür. Ancak aradaki fark istatistiki anlam ifade etmemiştir. Yine 13 yaş altı ve üstü hastaların karşılaşı̧ımasında da fark anlamlı bulunmamıştır. Yaş ve keros ilişkisinin daha büyük çalışma grupları ile çalışılması gerektiği kanaatindeyiz.

\section{Sonuç}

Bilgisayarlı tomografi ile anterior kafa tabanı incelemesi endoskopik sinüs cerrahisi öncesinde komplikasyon oranlarının azaltılması için her cerrah tarafından mutlaka yapılması gereken bir iş-
Sakarya Tıp Dergisi

2018;8(2):352-358

KARA ve Ark.

Paranazal Sinüs BT ile Keros ve

Kribriform Asimetrisinin Değerlendirilmesi 
lemdir. Çalışmada gerçekleştirilen ölçümler sonucunda istatistiki olarak anlam ifade etmese de asimetrik keros vakaları konusunda cerrahın dikkatli olması gerekliliği literatür ile uyumlu bir şekilde tekrar vurgulanmıştır. Pediatrik yaş grubundaki farkılıklar için ise geniş katılımcı sayıları ile çalışmanın tekrarlanması önerilebilir. 
1. Souza, S. A., Souza, M. M. A. D., Idagawa, M., Wolosker, Â. M. B., \& Ajzen, S. A. Computed tomography assessment of the ethmoid roof: a relevant region at risk in endoscopic sinus surgery. Radiologia Brasileira 2008;41(3), 143-147.

2. Keros, P. On the practical value of differences in the level of the lamina cribrosa of the ethmoid. Zeitschrift fur Laryngologie, Rhinologie, Otologie und ihre Grenzgebiete 1962; 41: 809-813.

3. Kaplanoglu, H., Kaplanoglu, V., Dilli, A., Toprak, U., \& Hekimoğlu, B. An analysis of the anatomic variations of the paranasal sinuses and ethmoid roof using computed tomography. The Eurasian journal of medicine 2013;45(2), 115.

4. Luong A, Marple BF. Sinus surgery: indications and techniques. Clin Rev Allergy Immunol 2006;30:217-22.

5. Stankiewicz JA. Complications of endoscopic intranasal ethmoidectomy. Laryngoscope 1987;97:1270-3.

6. Stammberger $\mathrm{H}$. Special endoscopic anatomy of the lateral nasal wall and ethmoidal sinuses. In: BC Decker, ed. Functional Sinus Surgery. Philadelphia, 1991; pp.49-87.

7. Gauba, V., Saleh, G. M., Dua, G., Agarwal, S., Ell, S., \& Vize, C. Radiological classification of anterior skull base anatomy prior to performing medial orbital wall decompression. Orbit 2006;25(2), 93-96.

8. Ohnishi T, Yanagisawa E. Lateral lamella of the cribriform plate - an important high-risk area in endoscopic sinus surgery. Ear Nose Throat J 1995;74:688-90.

9. Bașak, S., Akdilli, A., Karaman, C. Z., \& Kunt, T. Assessment of some important anatomical variations and dangerous areas of the paranasal sinuses by computed tomography in children. International journal of pediatric otorhinolaryngology 2000:55(2), 81-89.
10. Jang YJ, Park HM, Kim HG. The radiographic incidence of bony defects in the lateral lamella of the cribriform plate. Clin Otolaryngol Allied Sc 1999;24:440-2.

11. Leunig, A., Betz, C. S., Sommer, B., \& Sommer, F. Anatomic variation of the sinuses; multiplanar CT-analysis in 641 patients. Laryngo-rhinootologie 2008;87(7), 482-489.

12. Anderhuber, W., Walch, C., \& Fock, C. Configuration of ethmoid roof in children 0-14 years of age. Laryngo-rhino-otologie 2001;80(9), 509511

13. Basak, S., Karaman, C.Z., Akdilli, A., Mutlu, C., Odabasi, O., Erpek, G. Evaluation of some important anatomical variations and dangerous areas of the paranasal sinuses by CT for safer endonasal surgery, Rhinology 1998;36(4),162-167.

14. Güldner, C., Zimmermann, A. P., Diogo, I., Werner, J. A., \& Teymoortash, A. Age-dependent differences of the anterior skull base. International journal of pediatric otorhinolaryngology 2012;76(6), 822-828.

15. Wormald, P. J. Surgery of the frontal recess and frontal sinus. Rhinology $2005 ; 43(2), 82-5$.

16. Lebowitz, R. A., Terk, A., Jacobs, J. B., \& Holliday, R. A. Asymmetry of the ethmoid roof: analysis using coronal computed tomography. The Laryngoscope 2001;111(12), 2122-2124.

17. Dessi, P., Moulin, G., Triglia, J. M., Zanaret, M., \& Cannoni, M. Difference in the height of the right and left ethmoidal roofs: a possible risk facto for ethmoidal surgery. Prospective study of $150 \mathrm{CT}$ scans. The Journal of Laryngology \& Otology 1994;108(3), 261-262.

18. Elwany, S., Medanni, A., Eid, M., Aly, A., El-Daly, A., \& Ammar, S. R. Radiological observations on the olfactory fossa and ethmoid roof. The Journal of Laryngology \& Otology 2010;124(12), 1251-1256. $\pi$
$>$
$\prec$
$z$
$D$
$\pi$
$D$
$D$
$D$

Sakarya Tıp Dergisi

2018;8(2):352-358

KARA ve Ark.

Paranazal Sinüs BT ile Keros ve

Kribriform Asimetrisinin Değerlendirilmesi 